\title{
SYNTHESIS, ANTICANCER ACTIVITY AND MOLECULAR DOCKING STUDIES OF SOME NOVEL QUINOLINE HYDRAZIDE DERIVATIVES OF SUBSTITUTED BENZALDEHYDES
}

\author{
Venkatareddy Gayam, Subban Ravi*, G.M.V.N.A.R. Ravikumar \\ and Arumugam Thangamani \\ Department of Chemistry, Karpagam Academy of Higher Education, \\ Coimbatore, Tamilnadu, India \\ *E-mail : ravisubban@ rediffmail.com
}

\begin{abstract}
A novel series of quinoline hydrazide bridged derivatives were synthesized by a multistep reaction from vanillic acid. The reactions involved esterification, O-alkylation, nitration, reduction, cyclization, to get 7-(3chloropropoxy)-4-hydroxy-6-methoxyquinoline-3-carbonitrile $\mathbf{5}$ which further reacted with ethyl bromoacetate to yield the corresponding ester $\mathbf{6}$. Compound $\mathbf{6}$ react with hydrazine hydrate to afford the hydrazide 7, which then reacted with substituted benzaldehydes to afford the corresponding quinoline-hydrazides $\mathbf{8}-\mathbf{1 9}$. The synthesized compounds were characterized by IR, NMR and MS data. Compounds 7-19 were tested for their cytotoxic activity by Trypan blue, MTT and LDH assays. All the tested compounds showed cytotoxic activity and the results are comparable with the standard compound bosutinib. Compound 12 showed an $\mathrm{IC}_{50}$ value of $26.93 \pm 2.8$ and $28.92 \pm$ $1.6 \mu \mathrm{g} / \mathrm{ml}$ by MTT and trypan blue assay respectively. Structure activity relationship was discussed among the compounds 7-19. Molecular docking studies were carried out for all the compounds 7-19 against BCR-ABL T315I protein. Compound 12 showed very good interactions with the protein like any other tyrosine kinase inhibitors.

Keywords: Quinolinehydrazide, Bosutinib, Tyrosine Kinase Inhibitor, Molecular Docking
\end{abstract}

(C) RASĀYAN. All rights reserved

\section{INTRODUCTION}

Quinoline scaffold posses many types of biological activities and is an important construction motif for the development of new drugs. Substitution of the group in a suitable position of a bioactive molecule is found to exert a profound pharmacological effect ${ }^{1}$. Quinoline and its derivatives have been reported to show significant anticancer activity through a different mechanism of action such as growth inhibitors by cell cycle arrest, apoptosis, inhibition of angiogenesis, disruption of cell migration and modulation. Quinoline and its analogs have recently been examined for their modes of function in the inhibition of tyrosine kinases, proteasome, tubulin polymerization, topoisomerase and DNA repair, 2 . The quinoline nucleus is present in many alkaloids like campothecin with swaying antitumor activity ${ }^{4,5}$. The drugs like campothecin, camptosar, hycamtin are expensive and have pronounced side effects. The main problem with these agents is drug resistance which arises after some time and the toxicity due to their lack of specificity and kill healthy cells.

The quinoline-hydrazide-hydrazone motif and hydrazones possessing an azomethine $-\mathrm{NHN}=\mathrm{CH}$ - proton constitutes an important class of compounds for new drug development ${ }^{6}$. Recently in our laboratory, we have synthesized a series of cinnamoylated chloroquine analogs and reported their antimalarial activity. Further, a series of phenothiazine and rhodanine derivatives were synthesized as potential BCR-ABLT315I inhibitors. This prompted us to take the present work and develop a series of compounds containing quinoline and hydrazide motif which behave as anticancer agents.

Rasayan J. Chem., 12(2), 880-890(2019)

http://dx.doi.org/10.31788/RJC.2019.1225137

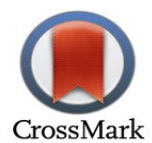




\section{General Methods}

\section{EXPERIMENTAL}

Melting points were uncorrected and obtained on an Electrothermal 9100 apparatus. Infrared spectra were recorded using a Shimadzu (8400) FT-IR spectrometer. ${ }^{1} \mathrm{H}(400 \mathrm{MHz})$ and ${ }^{13} \mathrm{C}(100 \mathrm{MHz}) \mathrm{NMR}$ spectral data were recorded on a Bruker Avance (AC 80) instrument. DMSO-d6 was used as a solvent. Chemical shifts were reported in parts per million ( $\mathrm{ppm}$ ) downfield from internal tetramethylsilane (TMS). All reactions were monitored by thin layer chromatography (TLC, Rf values) using silica gel 60 coated plates F254 (Merck, aluminium sheets). Visualization was performed by ultraviolet light at 254 and $354 \mathrm{~nm}$. Mass spectra were obtained by using a Waters LC/MS ZQ 2000 instrument. Solvents and reagents were used as supplied.

\section{7-(3-Chloropropoxy)-4-hydroxy-6-methoxyquinoline-3-carbonitrile, 5}

3,3-diethoxypropionitrile $(115 \mathrm{~mL})$ was added into a stirred mixture of $58 \mathrm{~mL}$ water and $230 \mathrm{~mL}$ trifluoro acetic acid at $0-10^{\circ} \mathrm{C}$ for $60 \mathrm{~min}$ and stirred for $4 \mathrm{~h}$. 2-amino-4-(3-chloroprpoxy)-5-methoxy benzoate $4(115 \mathrm{~g}, 0.420 \mathrm{~mol})$ in $460 \mathrm{~mL}$ ethylacetate was added into the reaction mixture in $30 \mathrm{~min}$ and stirred for another $30 \mathrm{~min}$. the $\mathrm{pH}$ of the reaction mixture was adjusted to 11-12 using sodium hydroxide $(25 \%)$ at room temperature. Then ethanol $1150 \mathrm{~mL}$ was added and stirred for $4-6 \mathrm{~h}$. The reaction mixture was poured into DM water and stirred for another $1 \mathrm{~h}$. The precipitated solid was filtered and dried for $5 \mathrm{~h}$ at $55-60^{\circ} \mathrm{C}$ under vacuum to obtain title compound $\mathbf{5}$ as yellow color solid $(104.5 \mathrm{~g}, 85.0 \%)$.

\section{Ethyl 2-(7-(3-chloropropoxy)-3-cyano-6-methoxyquinoline-4-yloxy) acetate, 6}

Ethyl bromoacetate $(30.0 \mathrm{~g}, 0.179 \mathrm{~mol})$ was added in $30 \mathrm{~min}$ to the stirred solution of $5(50.0 \mathrm{~g}, 0.171$ $\mathrm{mol})$ and $\mathrm{K}_{2} \mathrm{CO}_{3}(35.0 \mathrm{~g}, 0.257 \mathrm{~mol})$ in $200 \mathrm{~mL}$ of acetone at room temperature. The reaction mixture was heated to $55-60^{\circ} \mathrm{C}$ for $4 \mathrm{~h}$. Cooled to $25-30^{\circ} \mathrm{C}$ and the precipitated solid was filtered, washed with $50 \mathrm{~mL}$ of acetone and suck dried for $30 \mathrm{~min}$. The solid was once again stirred for $30 \mathrm{~min}$ in $250 \mathrm{~mL}$ of ethanol at $60-65^{\circ} \mathrm{C}$ and cooled to room temperature, filtered and dried at $55-60^{\circ} \mathrm{C}$ under vacuum to obtain title compound 6 as yellow color solid $(63.0 \mathrm{~g}, 98.0 \%)$.

\section{2-(7-(3-Chloropropoxy)-3-cyano-6-methoxyquinoline-4-yloxy) acetohydrazide, 7}

The solution of $6(55.0 \mathrm{~g}, 0.1452 \mathrm{~mol})$ in $550 \mathrm{~mL}$ of ethanol was stirred and hydrazine hydrate (99\%) $(25.0 \mathrm{~g}, 0.508 \mathrm{~mol})$ was added and further stirred for $5 \mathrm{~min}$ at room temperature and heated to $75-80^{\circ} \mathrm{C}$ for $4 \mathrm{~h}$. The precipitated solid was cooled, filtered, washed with $110 \mathrm{~mL}$ of ethanol and suck dried for 30 min. The solid was dispersed in $275 \mathrm{~mL}$ of ethanol for $1 \mathrm{~h}$, cooled, filtered and dried for $5 \mathrm{~h}$ at $65-70^{\circ} \mathrm{C}$ under vacuum yellow color solid compound 7 (50.3 g, 95.0\%).

General Synthesis for compounds, 8 - 19 (E)-N-(2-Methoxybenzylidene)-2-7-(3-chloropropoxy)-3cyano-6-methoxyquinoline-4-yloxy) acetohydrazide, 8

2-Methoxy benzaldehyde $(1.3 \mathrm{~g}, 0.0090 \mathrm{~mol})$ was added to the solution of compound $7(3.0 \mathrm{~g}, 0.0082$ $\mathrm{mol}$ ) in $30 \mathrm{~mL}$ of ethanol under stirring and stirred for another $5 \mathrm{~min}$ at room temperature. The catalytic amount of p-Toluene sulfonic acid was added and the reaction mixture was heated to $75-80^{\circ} \mathrm{C}$ for $4 \mathrm{~h}$. The precipitated solid was filtered, washed with $10 \mathrm{~mL}$ of ethanol and suck dry for $30 \mathrm{~min}$. The solid was slurried in $15 \mathrm{~mL}$ of ethanol for $1 \mathrm{~h}$, filtered and dried for $5 \mathrm{~h}$ at $65-70^{\circ} \mathrm{C}$ under vacuum to yield yellow color solid compound $\mathbf{8}$ (3.8 g, 97.0\%).

\section{7-(3-Chloropropoxy)-4-hydroxy-6-methoxyquinoline-3-carbonitrile, 5}

MS(ES) m/z 293.0, (M+1), IR(KBr) cm ${ }^{-1}, 666$ (C-Cl), 1278 (C-O-C), 1222 (COO-), 3300 and $884(\mathrm{NH})$, $1708(\mathrm{C}=\mathrm{O}), 1463(\mathrm{Ar}-\mathrm{CH})$ and $2213(\mathrm{CN})$.

Ethyl 2-(7-(3-Chloropropoxy)-3-cyano-6-methoxyquinoline-4-yloxy) acetate, 6 Yellow solid compound, Observed mass MS (ES) m/z 379.8(M+1), IR(KBr) $\mathrm{cm}^{-1}, 658$ (C-Cl), 1278 (C-OC), 1221 (COO-), 3324 and $878(\mathrm{NH}), 1682(\mathrm{C}=\mathrm{O}), 1463(\mathrm{Ar}-\mathrm{CH})$ and $2225(\mathrm{CN})$. 
RASĀYAN J. Chem.

Vol. 12 | No. 2 |880 - 890| April - June | 2019

2-(7-(3-chloropropoxy)-3cyano-6-methoxyquinoline-4-yloxy)acetohydrazide, 7

Yellow solid compound, Observed mass MS (ES) m/z 365.8(M+1), IR(KBr)cm ${ }^{-1}, 653$ (C-Cl), 1275 (C-OC), $1221(\mathrm{COO}-), 877(\mathrm{NH}), 1682(\mathrm{C}=\mathrm{O}), 1443(\mathrm{Ar}-\mathrm{CH}), 2226(\mathrm{CN})$.

\section{Compound, 8}

Yellow solid compound, Melting point: $268-272^{\circ} \mathrm{C}$, Observed mass MS(ES) $\mathrm{m} / \mathrm{z}=483.9(\mathrm{M}+1)$, IR $(\mathrm{KBr}) \mathrm{cm}^{-1}, 668(\mathrm{C}-\mathrm{Cl}), 1262(\mathrm{C}-\mathrm{O}-\mathrm{C}), 876(\mathrm{NH}), 1682(\mathrm{C}=\mathrm{O}), 1464(\mathrm{Ar}-\mathrm{CH})$ and $2221(\mathrm{CN})$.

\section{Compound, 9}

Yellow colour solid compound, Melting point: $267-273^{\circ} \mathrm{C}$, Observed mass MS (ES) $\mathrm{m} / \mathrm{z}=469.9(\mathrm{M}+1)$, IR (KBr), cm ${ }^{-1}$ : $665(\mathrm{C}-\mathrm{Cl}), 1278(\mathrm{C}-\mathrm{O}-\mathrm{C}), 884(\mathrm{NH}), 1703(\mathrm{C}=\mathrm{O}), 1465(\mathrm{Ar}-\mathrm{CH})$ and $2224(\mathrm{CN})$.

\section{Compound, 10}

Yellow colour solid compound, Melting point: $267-271^{\circ} \mathrm{C}$, Observed mass MS (ES) $\mathrm{m} / \mathrm{z}=499.9(\mathrm{M}+1)$, IR $(\mathrm{KBr}) \mathrm{cm}^{-1}$ : $661(\mathrm{C}-\mathrm{Cl}), 1279(\mathrm{C}-\mathrm{O}-\mathrm{C}), 3,100$ and $871(\mathrm{NH}), 1673(\mathrm{C}=\mathrm{O}), 1460(\mathrm{Ar}-\mathrm{CH}), 2222(\mathrm{CN})$ and $3219(-\mathrm{OH})$.

\section{Compound, 11}

Yellow colour solid compound, Melting point: $268-272^{\circ} \mathrm{C}$, Observed mass MS (ES) $\mathrm{m} / \mathrm{z}=498.9(\mathrm{M}+1)$, $\mathrm{IR}(\mathrm{KBr}) \mathrm{cm}^{-1}$ : $665(\mathrm{C}-\mathrm{Cl}), 1277(\mathrm{C}-\mathrm{O}-\mathrm{C}), 3213$ and $883(\mathrm{NH}), 1673(\mathrm{C}=\mathrm{O}), 1437(\mathrm{Ar}-\mathrm{CH}), 2221(\mathrm{CN})$ and $1345\left(-\mathrm{NO}_{2}\right)$.

\section{Compound, 12}

Yellow colour solid compound, Melting point: $267-271^{\circ} \mathrm{C}$, Observed mass MS (ES) $\mathrm{m} / \mathrm{z}=485.9(\mathrm{M}+1)$, $\mathrm{IR}(\mathrm{KBr}) \mathrm{cm}^{-1}$ : $654(\mathrm{C}-\mathrm{Cl}), 1280(\mathrm{C}-\mathrm{O}-\mathrm{C}), 3245$ and $868(\mathrm{NH}), 1680(\mathrm{C}=\mathrm{O}), 3051(\mathrm{Ar}-\mathrm{CH}), 2223(\mathrm{CN})$.

\section{Compound, 13}

Yellow colour solid compound, Melting point: $265-268^{\circ} \mathrm{C}$, Observed mass MS(ES) $\mathrm{m} / \mathrm{z}=469.9(\mathrm{M}+1)$, $\mathrm{IR}(\mathrm{KBr}) \mathrm{cm}^{-1}$ : $662(\mathrm{C}-\mathrm{Cl}), 1228(\mathrm{C}-\mathrm{O}-\mathrm{C}), 3212$ and $873(\mathrm{NH}), 1662(\mathrm{C}=\mathrm{O}), 3065(\mathrm{Ar}-\mathrm{OH})$, and $2228(\mathrm{CN})$.

\section{Compound, 14}

Yellow colour solid compound, Melting point: $267-272^{\circ} \mathrm{C}$, Observed mass $\mathrm{MS}(\mathrm{ES}) \mathrm{m} / \mathrm{z}=$ 498.9(M+1), IR(KBr) cm $\mathrm{cm}^{-1}: 666(\mathrm{C}-\mathrm{Cl}), 1278(\mathrm{C}-\mathrm{O}-\mathrm{C}), 3214$ and 884(NH), $1673(\mathrm{C}=\mathrm{O}), 1438(\mathrm{Ar}-\mathrm{CH})$, $2222(\mathrm{CN})$ and $1346\left(-\mathrm{NO}_{2}\right)$.

\section{Compound, 15}

Yellow colour solid compound, Melting point: $265-270^{\circ} \mathrm{C}$, Observed mass MS (ES) $\mathrm{m} / \mathrm{z}=$ 499.9(M+1), IR(KBr) cm $\mathrm{cm}^{-1}$ : 660(C-Cl), 1278(C-O-C), 3,199 and 870(NH), 1672(C=O), 1459(Ar- CH), $2221(\mathrm{CN})$ and $3218(-\mathrm{OH})$.

\section{Compound, 16}

Yellow colour solid compound, Melting point: $268-275^{\circ} \mathrm{C}$, Observed mass $\mathrm{MS}(\mathrm{ES}) \mathrm{m} / \mathrm{z}=$ 499.9(M+1), IR(KBr) cm $\mathrm{cm}^{-1}$ : 662(C-Cl), 1280(C-O-C), 3101 and 872(NH), 1674(C=O), 1461(Ar- CH), $2223(\mathrm{CN})$ and $3220(-\mathrm{OH})$.

\section{Compound, 17}

Yellow solid compound, Melting point: $268-273^{\circ} \mathrm{C}$, Observed mass $\mathrm{MS}(\mathrm{ES}) \mathrm{m} / \mathrm{z}=483.9(\mathrm{M}+1)$, $\mathrm{IR}(\mathrm{KBr}) \mathrm{cm}^{-1}, 669(\mathrm{C}-\mathrm{Cl}), 1263(\mathrm{C}-\mathrm{O}-\mathrm{C}), 877(\mathrm{NH}), 1683(\mathrm{C}=\mathrm{O}), 1465(\mathrm{Ar}-\mathrm{CH})$ and $2222(\mathrm{CN})$.

\section{Compound, 18}

Yellow colour solid compound, Melting point: $269-275^{\circ} \mathrm{C}$, Observed mass $\mathrm{MS}(\mathrm{ES}) \mathrm{m} / \mathrm{z}=$ 543.89(M+1), IR(KBr) $\mathrm{cm}^{-1}:$ 666(C-Cl), 1278(C-O-C), 3214 and 884(NH), 1674(C=O), 1438(Ar- CH), $2222(\mathrm{CN})$ and $1346\left(-\mathrm{NO}_{2}\right)$. 


\section{Compound, 19}

Yellow colour solid compound, Melting point: $268-273^{\circ} \mathrm{C}$, Observed mass MS (ES) $\mathrm{m} / \mathrm{z}=485.9(\mathrm{M}+1)$, $\operatorname{IR}(\mathrm{KBr}) \mathrm{cm}^{-1}$ : 655(C-Cl), 1281(C-O-C), 3246 and $868(\mathrm{NH}), 1681(\mathrm{C}=\mathrm{O}), 3052(\mathrm{Ar}-\mathrm{CH}), 2224(\mathrm{CN})$.

\section{RESULTS AND DISCUSSION}

The synthesis of final and intermediate compounds was performed as outlined in Schemes-1 and 2. Synthesis of the intermediate 1, 2, 3 and 4were prepared following literature methods ${ }^{7}$. The intermediate 5 (7-(3-Chloropropoxy) -4-hydroxy-6-methoxyquinoline-3-carbonitrile) was prepared by the reaction of 4 with 3,3-diethoxypropionitrile in the presence of trifluoroacetic acid as the catalyst followed by the treatment with sodium hydroxide. This cyclisation of $\mathbf{4}$ to $\mathbf{5}$ takes place in one step in contrast with the procedure reported in the literature, where it takes place in two steps ${ }^{6}$. Compound $\mathbf{5}$ is the key intermediate to bosutinib an adenosine triphosphate (ATP)-competitive Bcr-Abl tyrosine-kinase inhibitor with an additional inhibitory effect on Src family kinases (including Src, Lyn, and Hck) for use in the treatment of cancer ${ }^{8}$.In order to generate a diverse array of analogues, a convergent synthesis was envisaged, whereby the targeted hydrazide-hydrazone structure could be formed by an amide-coupling reaction between an ester and hydrazine hydrate followed by a reaction with substituted benzaldehydes.In Scheme-2 compound $\mathbf{6}$ was prepared by treating 5 with ethylbromo acetate in the presence of potassium carbonate as an acid scavenger in acetone media. Then the compound $\mathbf{6}$ was reacted with hydrazine hydrate at $80^{\circ} \mathrm{C}$ in ethanol, cooled and filtered to get final intermediate 7 . Finally substituted quinoline derivatives 8-19 were prepared by condensation of the intermediate 7 with differently substituted benzaldehydes using p-TSA as the catalyst in ethanol media at $75-80^{\circ} \mathrm{C}$. In the substituted benzaldehydes both electron withdrawing $\left(-\mathrm{NO}_{2}\right)$ group and electron donating groups like $-\mathrm{OH}$, $-\mathrm{OCH}_{3}$ were used. In the substitution pattern ortho and Para positions were used to prepare monosubstituted products and the Meta and Para positions were used to prepare the disubstituted products (Fig.-1).

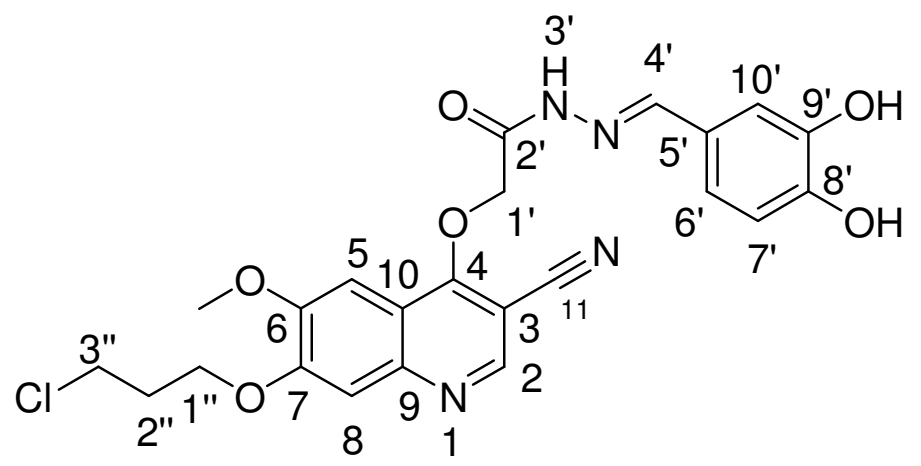

Fig.-1: Substituted Quinolone Derivative

Table-1: ${ }^{1} \mathrm{H}$ NMR Spectral Data of the Compounds 8-19

\begin{tabular}{|c|c|c|c|c|c|c|c|c|c|c|c|c|}
\hline $\mathrm{H}^{\mathrm{I}}$ & 8 & 9 & 10 & 11 & 12 & 13 & 14 & 15 & 16 & 17 & 18 & 19 \\
\hline 2 & $8.76(1 \mathrm{H}, \mathrm{s})$ & $\begin{array}{c}8.76 \\
(1 \mathrm{H}, \mathrm{s})\end{array}$ & $\begin{array}{c}8.76 \\
(1 \mathrm{H}, \mathrm{s})\end{array}$ & $\begin{array}{c}8.7 \\
(1 \mathrm{H}, \mathrm{s} \\
\quad)\end{array}$ & $\begin{array}{c}8.7, \\
(1 \mathrm{H}, \mathrm{s} \\
)\end{array}$ & $\begin{array}{c}8.77 \\
(1 \mathrm{H}, \mathrm{s} \\
)\end{array}$ & $\begin{array}{c}8.71, \\
(1 \mathrm{H}, \mathrm{s})\end{array}$ & $\begin{array}{c}8.76 \\
(1 \mathrm{H}, \mathrm{s})\end{array}$ & $\begin{array}{c}8.76 \\
(1 \mathrm{H}, \mathrm{s})\end{array}$ & $\begin{array}{c}8.76 \\
(1 \mathrm{H}, \mathrm{s} \\
)\end{array}$ & $\begin{array}{c}8.7 \\
(1 \mathrm{H}, \mathrm{s})\end{array}$ & $\begin{array}{c}8.7 \\
(1 \mathrm{H}, \mathrm{s})\end{array}$ \\
\hline 5 & $7.57(1 \mathrm{H}, \mathrm{s})$ & $\begin{array}{c}7.58 \\
(1 \mathrm{H}, \mathrm{s})\end{array}$ & $\begin{array}{c}7.57 \\
(1 \mathrm{H}, \mathrm{s})\end{array}$ & $\begin{array}{c}7.58, \\
(1 \mathrm{H}, \mathrm{s} \\
)\end{array}$ & $\begin{array}{c}7.58, \\
(1 \mathrm{H}, \mathrm{s} \\
)\end{array}$ & $\begin{array}{c}7.57 \\
(1 \mathrm{H}, \mathrm{s} \\
)\end{array}$ & $\begin{array}{c}7.59, \\
(1 \mathrm{H}, \mathrm{s})\end{array}$ & $\begin{array}{c}7.57 \\
(1 \mathrm{H}, \mathrm{s})\end{array}$ & $\begin{array}{c}7.57 \\
(1 \mathrm{H}, \mathrm{s})\end{array}$ & $\begin{array}{c}7.57 \\
(1 \mathrm{H}, \mathrm{s} \\
)\end{array}$ & $\begin{array}{c}7.58, \\
(1 \mathrm{H}, \mathrm{s})\end{array}$ & $\begin{array}{c}7.58, \\
(1 \mathrm{H}, \mathrm{s})\end{array}$ \\
\hline 8 & $7.05,(1 \mathrm{H}, \mathrm{s})$ & $\begin{array}{c}7.06, \\
(1 \mathrm{H}, \mathrm{s})\end{array}$ & $\begin{array}{c}7.06, \\
(1 \mathrm{H}, \mathrm{s})\end{array}$ & $\begin{array}{c}7.04, \\
(1 \mathrm{H}, \mathrm{s} \\
)\end{array}$ & $\begin{array}{c}7.04, \\
(1 \mathrm{H}, \mathrm{s} \\
)\end{array}$ & $\begin{array}{c}7.05, \\
(1 \mathrm{H}, \mathrm{s} \\
)\end{array}$ & $\begin{array}{c}7.05, \\
(1 \mathrm{H}, \mathrm{s})\end{array}$ & $\begin{array}{c}7.06, \\
(1 \mathrm{H}, \mathrm{s})\end{array}$ & $\begin{array}{c}7.06, \\
(1 \mathrm{H}, \mathrm{s})\end{array}$ & $\begin{array}{c}7.05, \\
(1 \mathrm{H}, \mathrm{s} \\
)\end{array}$ & $\begin{array}{c}7.04, \\
(1 \mathrm{H}, \mathrm{s})\end{array}$ & $\begin{array}{c}7.04, \\
(1 \mathrm{H}, \mathrm{s})\end{array}$ \\
\hline $1^{\prime}$ & $5.63,(2 \mathrm{H}, \mathrm{s})$ & $\begin{array}{c}5.60, \\
(2 \mathrm{H}, \mathrm{s})\end{array}$ & $\begin{array}{c}5.64, \\
(2 \mathrm{H}, \mathrm{s})\end{array}$ & $\begin{array}{c}5.06, \\
(2 \mathrm{H}, \mathrm{s} \\
)\end{array}$ & $\begin{array}{c}5.60, \\
(2 \mathrm{H}, \mathrm{s} \\
)\end{array}$ & $\begin{array}{c}5.60, \\
(2 \mathrm{H}, \mathrm{s} \\
)\end{array}$ & $\begin{array}{c}5.07, \\
(2 \mathrm{H}, \mathrm{s})\end{array}$ & $\begin{array}{c}5.64, \\
(2 \mathrm{H}, \mathrm{s})\end{array}$ & $\begin{array}{c}5.64, \\
(2 \mathrm{H}, \mathrm{s})\end{array}$ & $\begin{array}{c}5.63, \\
(2 \mathrm{H}, \mathrm{s} \\
)\end{array}$ & $\begin{array}{c}5.06, \\
(2 \mathrm{H}, \mathrm{s})\end{array}$ & $\begin{array}{c}5.60, \\
(2 \mathrm{H}, \mathrm{s})\end{array}$ \\
\hline $4 '$ & $8.05(1 \mathrm{H}, \mathrm{s})$ & $\begin{array}{c}8.42(1 \mathrm{H} \\
, \mathrm{s})\end{array}$ & $\begin{array}{c}8.00(1 \mathrm{H} \\
\mathrm{s})\end{array}$ & $\begin{array}{c}7.9 \\
(1 \mathrm{H}, \\
\mathrm{s})\end{array}$ & $\begin{array}{c}7.93 \\
(1 \mathrm{H} \\
\mathrm{s})\end{array}$ & $\begin{array}{c}8.01 \\
(1 \mathrm{H}, \\
\mathrm{s})\end{array}$ & $\begin{array}{c}7.91 \\
(1 \mathrm{H}, \mathrm{s})\end{array}$ & $\begin{array}{c}8.00 \\
(1 \mathrm{H}, \mathrm{s})\end{array}$ & $\begin{array}{c}8.00 \\
(1 \mathrm{H}, \\
\mathrm{s})\end{array}$ & $\begin{array}{c}8.05 \\
(1 \mathrm{H}, \\
\mathrm{s})\end{array}$ & $\begin{array}{c}7.9 \\
(1 \mathrm{H}, \mathrm{s})\end{array}$ & $\begin{array}{c}7.93 \\
(1 \mathrm{H}, \mathrm{s})\end{array}$ \\
\hline
\end{tabular}


RASĀYAN J. Chem.

Vol. 12 | No. 2 |880 - 890| April - June | 2019

\begin{tabular}{|c|c|c|c|c|c|c|c|c|c|c|c|c|}
\hline 6 & $7.02(1 \mathrm{H}, \mathrm{m})$ & $\begin{array}{c}6.89(1 \mathrm{H} \\
, \mathrm{m})\end{array}$ & $\begin{array}{c}7.17(1 \mathrm{H}, \mathrm{d} \\
\mathrm{dJ}=8.0 \\
1.6 \mathrm{~Hz})\end{array}$ & $\begin{array}{c}7.03 \\
(1 \mathrm{H}, \\
\mathrm{m})\end{array}$ & $\begin{array}{c}7.03 \\
(1 \mathrm{H}, \\
\mathrm{m})\end{array}$ & $\begin{array}{c}6.85 \\
(1 \mathrm{H}, \\
\mathrm{m})\end{array}$ & $\begin{array}{c}7.04 \\
(1 \mathrm{H}, \mathrm{m} \\
)\end{array}$ & $\begin{array}{c}7.18 \\
(1 \mathrm{H}, \mathrm{ddJ} J \\
=8.0, \\
1.6 \mathrm{~Hz})\end{array}$ & $\begin{array}{c}7.17 \\
(1 \mathrm{H}, \mathrm{d} \\
\mathrm{d}, \\
\mathrm{J}=8.0, \\
1.6 \mathrm{~Hz} \\
)\end{array}$ & $\begin{array}{c}7.02 \\
(1 \mathrm{H}, \\
\mathrm{m})\end{array}$ & $\begin{array}{c}7.03 \\
(1 \mathrm{Hm})\end{array}$ & $\begin{array}{c}7.03 \\
(1 \mathrm{H}, \mathrm{m})\end{array}$ \\
\hline $7^{\prime}$ & $\begin{array}{c}7.04(1 \mathrm{H}, \mathrm{d}, \\
\mathrm{J}=8 \mathrm{~Hz})\end{array}$ & $\begin{array}{c}6.93 \\
(1 \mathrm{H}, \mathrm{m})\end{array}$ & $\begin{array}{c}6.88 \\
(1 \mathrm{H}, \mathrm{d}, \mathrm{J}=8 \\
\mathrm{Hz})\end{array}$ & $\begin{array}{c}6.8 \\
(1 \mathrm{H}, \\
\mathrm{d}, \\
\mathrm{J}=8 \\
\mathrm{~Hz})\end{array}$ & $\begin{array}{c}6.82 \\
(1 \mathrm{H}, \\
\mathrm{d}, \\
\mathrm{J}=8 \\
\mathrm{~Hz})\end{array}$ & $\begin{array}{c}6.87 \\
(1 \mathrm{H}, \\
\mathrm{d}, \\
\mathrm{J}=8 \\
\mathrm{~Hz})\end{array}$ & $\begin{array}{c}6.81 \\
(1 \mathrm{H}, \mathrm{d}, \\
\mathrm{J}=8 \\
\mathrm{~Hz})\end{array}$ & $\begin{array}{c}6.89 \\
(1 \mathrm{H}, \mathrm{d} \\
\mathrm{J}=8 \mathrm{~Hz})\end{array}$ & $\begin{array}{c}6.88 \\
(1 \mathrm{H}, \mathrm{d}, \\
\mathrm{J}=8 \\
\mathrm{~Hz})\end{array}$ & $\begin{array}{c}7.04 \\
(1 \mathrm{H}, \\
\mathrm{d}, \\
\mathrm{J}=8 \\
\mathrm{~Hz})\end{array}$ & $\begin{array}{c}6.8 \\
(1 \mathrm{H}, \mathrm{d}, \\
\mathrm{J}=8 \\
\mathrm{~Hz})\end{array}$ & - \\
\hline $8^{\prime}$ & $\begin{array}{c}7.74(1 \mathrm{H}, \mathrm{d}, \\
\mathrm{J}=8 \mathrm{~Hz})\end{array}$ & $\begin{array}{c}7.31(1 \mathrm{H} \\
, \mathrm{t}, \mathrm{J}=8 \\
\mathrm{~Hz})\end{array}$ & - & - & - & - & $\begin{array}{c}7.2 \\
(1 \mathrm{H}, \mathrm{d}, \\
\mathrm{J}=1.6 \\
\mathrm{~Hz})\end{array}$ & - & - & & - & $\begin{array}{c}6.82 \\
(1 \mathrm{H}, \mathrm{d}, \\
\mathrm{J}=8 \\
\mathrm{~Hz})\end{array}$ \\
\hline $9^{\prime}$ & $\begin{array}{c}7.74(1 \mathrm{H}, \mathrm{d}, \\
\mathrm{J}=8 \mathrm{~Hz})\end{array}$ & $\begin{array}{c}7.87 \\
(1 \mathrm{H}, \mathrm{d} \\
\mathrm{J}=8 \mathrm{~Hz})\end{array}$ & - & - & - & $\begin{array}{c}7.66 \\
(1 \mathrm{H}, \\
\mathrm{d}, \\
\mathrm{J}=8 \\
\mathrm{~Hz})\end{array}$ & - & $\begin{array}{c}7.41(1 \\
\mathrm{H}, \mathrm{d}, \\
\mathrm{J}=1.6 \mathrm{H} \\
\mathrm{z})\end{array}$ & - & $\begin{array}{c}7.74( \\
1 \mathrm{H}, \\
\mathrm{d}, \\
\mathrm{J}=8 \\
\mathrm{~Hz})\end{array}$ & $\begin{array}{c}7.2 \\
(1 \mathrm{H}, \mathrm{d}, \mathrm{J} \\
=1.6 \\
\mathrm{~Hz})\end{array}$ & - \\
\hline 10 & - & - & $\begin{array}{c}7.41(1 \mathrm{H}, \mathrm{d}, \\
\mathrm{J}=1.6 \mathrm{~Hz})\end{array}$ & $\begin{array}{c}7.2 \\
(1 \mathrm{H}, \\
\mathrm{d}, \\
\mathrm{J}=1.6 \\
\mathrm{~Hz})\end{array}$ & $\begin{array}{c}7.2 \\
(1 \mathrm{H}, \\
\mathrm{d}, \\
\mathrm{J}=1.6 \\
\mathrm{~Hz})\end{array}$ & $\begin{array}{c}7.66 \\
(1 \mathrm{H}, \\
\mathrm{d}, \\
\mathrm{J}=8 \\
\mathrm{~Hz})\end{array}$ & - & - & $\begin{array}{c}7.42(1 \\
\mathrm{H}, \mathrm{d}, \\
\mathrm{J}=1.6 \\
\mathrm{~Hz})\end{array}$ & $\begin{array}{c}7.71( \\
1 \mathrm{H}, \\
\mathrm{d}, \\
\mathrm{J}=8 \\
\mathrm{~Hz})\end{array}$ & & $\begin{array}{c}7.2 \\
(1 \mathrm{H}, \mathrm{d}, \mathrm{J} \\
=1.6 \\
\mathrm{~Hz})\end{array}$ \\
\hline $1^{\prime}$ & $\begin{array}{c}4.11(2 \mathrm{H}, \mathrm{t} \\
\mathrm{J}=6.2 \mathrm{~Hz})\end{array}$ & $\begin{array}{c}4.11 \\
(2 \mathrm{H}, \mathrm{t}, \\
\mathrm{J}=6.2 \\
\mathrm{~Hz})\end{array}$ & $\begin{array}{c}4.11(2 \mathrm{H} \\
\mathrm{t}, \mathrm{J}=6.2 \\
\mathrm{~Hz})\end{array}$ & $\begin{array}{c}4.11 \\
(2 \mathrm{H}, \\
\mathrm{t}, \\
\mathrm{J}=6.2 \\
\mathrm{~Hz})\end{array}$ & $\begin{array}{c}4.11 \\
(2 \mathrm{H}, \\
\mathrm{t}, \\
\mathrm{J}=6.2 \\
\mathrm{~Hz})\end{array}$ & $\begin{array}{c}4.12 \\
(2 \mathrm{H}, \\
\mathrm{t}, \\
\mathrm{J}=6.2 \\
\mathrm{~Hz})\end{array}$ & $\begin{array}{c}4.12 \\
(2 \mathrm{H}, \mathrm{t}, \\
\mathrm{J}=6.2 \\
\mathrm{~Hz})\end{array}$ & $\begin{array}{c}4.11 \\
(2 \mathrm{H}, \mathrm{t} \\
\mathrm{J}=6.2 \\
\mathrm{~Hz})\end{array}$ & $\begin{array}{c}4.11 \\
(2 \mathrm{H}, \mathrm{t}, \\
\mathrm{J}=6.2 \\
\mathrm{~Hz})\end{array}$ & $\begin{array}{c}4.11 \\
(2 \mathrm{H}, \mathrm{t} \\
\mathrm{J} \\
\mathrm{J}=6.2 \\
\mathrm{~Hz})\end{array}$ & $\begin{array}{c}4.11 \\
(2 \mathrm{H}, \mathrm{t}, \\
\mathrm{J}=6.2 \\
\mathrm{~Hz})\end{array}$ & $\begin{array}{c}4.11 \\
(2 \mathrm{H}, \mathrm{t}, \\
\mathrm{J}=6.2 \\
\mathrm{~Hz})\end{array}$ \\
\hline 2 & $2.06(2 \mathrm{H}, \mathrm{m})$ & $\begin{array}{c}2.08(2 \mathrm{H} \\
, \mathrm{m})\end{array}$ & $\begin{array}{c}2.09(2 \mathrm{H}, \mathrm{m} \\
)\end{array}$ & $\begin{array}{c}2.07( \\
2 \mathrm{H}, \\
\mathrm{m})\end{array}$ & $\begin{array}{c}2.07( \\
2 \mathrm{H}, \\
\mathrm{m})\end{array}$ & $\begin{array}{l}2.04( \\
2 \mathrm{H}, \\
\mathrm{m})\end{array}$ & $\begin{array}{l}2.07(2 \\
\mathrm{H}, \mathrm{m})\end{array}$ & $\begin{array}{c}2.092 \mathrm{H}, \\
\mathrm{m})\end{array}$ & $\begin{array}{l}2.09(2 \\
\mathrm{H}, \mathrm{m})\end{array}$ & $\begin{array}{l}2.06 \\
2 \mathrm{H} \\
\mathrm{m})\end{array}$ & $\begin{array}{l}2.072 \\
\mathrm{H}, \mathrm{m})\end{array}$ & $\begin{array}{l}2.072 \\
\mathrm{H}, \mathrm{m})\end{array}$ \\
\hline $3^{\prime}$ & $\begin{array}{c}3.65(2 \mathrm{H}, \mathrm{t}, \\
\mathrm{J}=6.4 \mathrm{~Hz})\end{array}$ & $\begin{array}{c}4.25 \\
(2 \mathrm{H}, \mathrm{t}, \\
\mathrm{J}=6.2 \\
\mathrm{~Hz})\end{array}$ & $\begin{array}{c}3.65(2 \mathrm{H}, \\
\mathrm{t}, \mathrm{J}=6.4 \\
\mathrm{~Hz})\end{array}$ & $\begin{array}{c}3.66 \\
(2 \mathrm{H}, \\
t, \\
\mathrm{~J}=6.4 \\
\mathrm{~Hz})\end{array}$ & $\begin{array}{c}3.66 \\
(2 \mathrm{H}, \\
\mathrm{t}, \\
\mathrm{J}=6.4 \\
\mathrm{~Hz})\end{array}$ & $\begin{array}{c}3.66 \\
(2 \mathrm{H}, \\
t, \\
\mathrm{~J}=6.4 \\
\mathrm{~Hz})\end{array}$ & $\begin{array}{c}3.66 \\
(2 \mathrm{H}, \mathrm{t}, \\
\mathrm{J}=6.4 \\
\mathrm{~Hz})\end{array}$ & $\begin{array}{c}3.65 \\
(2 \mathrm{H}, \mathrm{t}, \\
\mathrm{J}=6.4 \\
\mathrm{~Hz})\end{array}$ & $\begin{array}{c}3.65 \\
(2 \mathrm{H}, \mathrm{t}, \\
\mathrm{J}=6.4 \\
\mathrm{~Hz})\end{array}$ & $\begin{array}{c}3.65 \\
(2 \mathrm{H}, \mathrm{t} \\
, \\
\mathrm{J}=6.4 \\
\mathrm{~Hz})\end{array}$ & $\begin{array}{c}3.66 \\
(2 \mathrm{H}, \mathrm{t}, \\
\mathrm{J}=6.4 \\
\mathrm{~Hz})\end{array}$ & $\begin{array}{c}3.66 \\
(2 \mathrm{H}, \mathrm{t}, \\
\mathrm{J}=6.4 \\
\mathrm{~Hz})\end{array}$ \\
\hline $\begin{array}{l}\mathrm{M} \\
\mathrm{eO}\end{array}$ & $\begin{array}{l}3.79(3 \mathrm{H}, \mathrm{s}) \\
3.81(3 \mathrm{H}, \mathrm{s})\end{array}$ & $\begin{array}{c}3.89 \\
(3 \mathrm{H}, \mathrm{s})\end{array}$ & $\begin{array}{c}3.79 \\
(3 \mathrm{H}, \mathrm{s}), \\
3.64 \\
(3 \mathrm{H}, \mathrm{s})\end{array}$ & $\begin{array}{c}3.80 \\
(3 \mathrm{H} \\
\mathrm{s})\end{array}$ & $\begin{array}{c}3.89 \\
(3 \mathrm{H}, \\
\mathrm{s})\end{array}$ & $\begin{array}{c}3.89 \\
(3 \mathrm{H}, \\
\mathrm{s})\end{array}$ & $\begin{array}{c}3.80 \\
(3 \mathrm{H}, \mathrm{s})\end{array}$ & $\begin{array}{c}3.79 \\
(3 \mathrm{H}, \mathrm{s}), \\
3.64(3 \\
\mathrm{H}, \mathrm{s})\end{array}$ & $\begin{array}{c}3.79 \\
(3 \mathrm{H}, \\
\mathrm{s}), \\
3.64 \\
(3 \mathrm{H}, \\
\mathrm{s})\end{array}$ & $\begin{array}{c}3.79 \\
(3 \mathrm{H}, \mathrm{s} \\
), \\
3.81( \\
3 \mathrm{H}, \\
\mathrm{s})\end{array}$ & $\begin{array}{c}3.80 \\
(3 \mathrm{H}, \mathrm{s})\end{array}$ & $\begin{array}{c}3.89 \\
(3 \mathrm{H}, \mathrm{s})\end{array}$ \\
\hline
\end{tabular}

${ }^{13} \mathrm{C}$-NMR spectra exhibited characteristic signals at $\delta 172.7$ for the carbonyl carbon, at $\delta 31.11,41.53$ and 65.53 for the carbons of the 3-chloropropoxy group and at $\delta 55.8$ for methoxy carbon. It also exhibited signals at $\delta 119.86$ for $\mathrm{CN}$ carbon(C-11'), 79.09 for the methylene carbon in between oxygen and carbonyl functions $\left(\mathrm{C}^{-1}{ }^{\prime}\right)$ and at 145.5 for $\mathrm{C}=\mathrm{N}$ carbon $(\mathrm{C}-4$ '). All the aromatic carbons appeared between $\delta 93.01$ and 152.71 .

Table-2: ${ }^{13} \mathrm{C}$ NMR Spectral Data of the Compounds 8-19

\begin{tabular}{c|c|c|c|c|c|c|c|c|c|c|c|c}
\hline $\mathrm{C}$ & 8 & 9 & 10 & 11 & 12 & 13 & 14 & 15 & 16 & 17 & 18 & 19 \\
\hline 2 & 147.8 & 147.9 & 147.9 & 147.9 & 147.9 & 147.8 & 147.9 & 147.9 & 147.9 & 147.8 & 147.9 & 147.9 \\
& 8 & 6 & 6 & 2 & 0 & 7 & 2 & 6 & 6 & 8 & 2 & 0 \\
\hline 3 & 93.00 & 93.03 & 92.99 & 93.11 & 93.01 & 92.88 & 93.11 & 92.99 & 92.99 & 93.00 & 93.11 & 93.01 \\
\hline 4 & 167.1 & 167.2 & 167.1 & 167.8 & 167.3 & 167.0 & 167.8 & 167.1 & 167.1 & 167.1 & 167.8 & 167.3 \\
& 8 & 4 & 9 & 5 & 0 & 3 & 5 & 9 & 9 & 8 & 5 & 0 \\
\hline 5 & 100.3 & 100.3 & 100.3 & 100.3 & 100.4 & 100.2 & 100.3 & 100.3 & 100.3 & 100.3 & 100.3 & 100.4 \\
& 1 & 5 & 4 & 5 & 0 & 5 & 5 & 4 & 4 & 1 & 5 & 0 \\
\hline
\end{tabular}


RASĀYAN J. Chem.

Vol. 12 | No. 2 |880 - 890| April - June | 2019

\begin{tabular}{|c|c|c|c|c|c|c|c|c|c|c|c|c|}
\hline 6 & $\begin{array}{c}150.4 \\
7\end{array}$ & $\begin{array}{c}150.4 \\
2\end{array}$ & $\begin{array}{c}150.4 \\
2\end{array}$ & $\begin{array}{c}152.7 \\
1\end{array}$ & $\begin{array}{c}150.4 \\
6\end{array}$ & $\begin{array}{c}150.4 \\
9\end{array}$ & $\begin{array}{c}152.7 \\
1\end{array}$ & $\begin{array}{c}150.4 \\
2\end{array}$ & $\begin{array}{c}150.4 \\
2\end{array}$ & $\begin{array}{c}150.4 \\
7\end{array}$ & $\begin{array}{c}152.7 \\
1\end{array}$ & $\begin{array}{c}150.4 \\
6\end{array}$ \\
\hline 7 & $\begin{array}{c}152.6 \\
7\end{array}$ & $\begin{array}{c}152.6 \\
8\end{array}$ & $\begin{array}{c}152.6 \\
6\end{array}$ & $\begin{array}{c}150.3 \\
7\end{array}$ & $\begin{array}{c}152.7 \\
1\end{array}$ & $\begin{array}{c}152.6 \\
8\end{array}$ & $\begin{array}{c}150.3 \\
7\end{array}$ & $\begin{array}{c}152.6 \\
6\end{array}$ & $\begin{array}{c}152.6 \\
6\end{array}$ & $\begin{array}{c}152.6 \\
7\end{array}$ & $\begin{array}{c}150.3 \\
7\end{array}$ & $\begin{array}{c}152.7 \\
1\end{array}$ \\
\hline 8 & $\begin{array}{c}105.2 \\
1\end{array}$ & $\begin{array}{c}105.2 \\
0\end{array}$ & $\begin{array}{c}105.1 \\
9\end{array}$ & $\begin{array}{c}105.2 \\
4\end{array}$ & $\begin{array}{c}105.2 \\
5\end{array}$ & $\begin{array}{c}105.2 \\
1\end{array}$ & $\begin{array}{c}105.2 \\
4\end{array}$ & $\begin{array}{c}105.1 \\
9\end{array}$ & $\begin{array}{c}105.1 \\
9\end{array}$ & $\begin{array}{c}105.2 \\
1\end{array}$ & $\begin{array}{c}105.2 \\
4\end{array}$ & $\begin{array}{c}105.2 \\
5\end{array}$ \\
\hline 9 & $\begin{array}{c}144.9 \\
2\end{array}$ & $\begin{array}{c}147.8 \\
9\end{array}$ & $\begin{array}{c}145.5 \\
7\end{array}$ & $\begin{array}{c}148.1 \\
0\end{array}$ & $\begin{array}{c}145.6 \\
7\end{array}$ & $\begin{array}{c}145.3 \\
9\end{array}$ & $\begin{array}{c}148.1 \\
0\end{array}$ & $\begin{array}{c}145.5 \\
7\end{array}$ & $\begin{array}{c}145.5 \\
7\end{array}$ & $\begin{array}{c}144.9 \\
2\end{array}$ & $\begin{array}{c}148.1 \\
0\end{array}$ & $\begin{array}{c}145.6 \\
7\end{array}$ \\
\hline 10 & $\begin{array}{c}114.3 \\
0\end{array}$ & $\begin{array}{c}116.5 \\
0\end{array}$ & $\begin{array}{c}115.4 \\
3\end{array}$ & $\begin{array}{c}114.2 \\
0\end{array}$ & $\begin{array}{c}115.5 \\
3\end{array}$ & $\begin{array}{c}115.6 \\
0\end{array}$ & $\begin{array}{c}114.2 \\
0\end{array}$ & $\begin{array}{c}115.4 \\
3\end{array}$ & $\begin{array}{c}115.4 \\
3\end{array}$ & $\begin{array}{c}114.3 \\
0\end{array}$ & $\begin{array}{c}114.2 \\
0\end{array}$ & $\begin{array}{c}115.5 \\
3\end{array}$ \\
\hline 11 & $\begin{array}{c}116.5 \\
0\end{array}$ & $\begin{array}{c}119.8 \\
4\end{array}$ & $\begin{array}{c}125.1 \\
2\end{array}$ & $\begin{array}{c}116.5 \\
0\end{array}$ & $\begin{array}{c}119.8 \\
6\end{array}$ & $\begin{array}{c}119.8 \\
2\end{array}$ & $\begin{array}{c}116.5 \\
0\end{array}$ & $\begin{array}{c}125.1 \\
2\end{array}$ & $\begin{array}{c}125.1 \\
2\end{array}$ & $\begin{array}{c}116.5 \\
0\end{array}$ & $\begin{array}{c}116.5 \\
0\end{array}$ & $\begin{array}{c}119.8 \\
6\end{array}$ \\
\hline $1^{\prime}$ & 65.49 & 65.80 & 65.48 & 65.57 & 79.09 & 65.48 & 65.57 & 65.48 & 65.48 & 65.49 & 65.57 & 79.09 \\
\hline $2^{\prime}$ & $\begin{array}{c}172.7 \\
2\end{array}$ & $\begin{array}{c}172.7 \\
3\end{array}$ & $\begin{array}{c}172.7 \\
2\end{array}$ & $\begin{array}{c}172.7 \\
0\end{array}$ & $\begin{array}{c}172.7 \\
4\end{array}$ & $\begin{array}{c}172.7 \\
3\end{array}$ & $\begin{array}{c}172.7 \\
0\end{array}$ & $\begin{array}{c}172.7 \\
2\end{array}$ & $\begin{array}{c}172.7 \\
2\end{array}$ & $\begin{array}{c}172.7 \\
2\end{array}$ & $\begin{array}{c}172.7 \\
0\end{array}$ & $\begin{array}{c}172.7 \\
4\end{array}$ \\
\hline 4 ' & $\begin{array}{c}135.4 \\
5\end{array}$ & $\begin{array}{c}142.2 \\
2\end{array}$ & $\begin{array}{c}147.8 \\
9\end{array}$ & $\begin{array}{c}140.4 \\
1\end{array}$ & $\begin{array}{c}145.5 \\
0\end{array}$ & $\begin{array}{c}135.4 \\
0\end{array}$ & $\begin{array}{c}140.4 \\
1\end{array}$ & $\begin{array}{c}147.8 \\
9\end{array}$ & $\begin{array}{c}147.8 \\
9\end{array}$ & $\begin{array}{c}135.4 \\
5\end{array}$ & $\begin{array}{c}140.4 \\
1\end{array}$ & $\begin{array}{c}145.5 \\
0\end{array}$ \\
\hline 5 & $\begin{array}{c}116.5 \\
5\end{array}$ & $\begin{array}{c}119.4 \\
1\end{array}$ & $\begin{array}{c}118.1 \\
0\end{array}$ & $\begin{array}{c}128.0 \\
6\end{array}$ & $\begin{array}{c}116.5 \\
4\end{array}$ & $\begin{array}{c}116.5 \\
4\end{array}$ & $\begin{array}{c}128.0 \\
6\end{array}$ & $\begin{array}{c}118.1 \\
0\end{array}$ & $\begin{array}{c}118.1 \\
0\end{array}$ & $\begin{array}{c}116.5 \\
5\end{array}$ & $\begin{array}{c}128.0 \\
6\end{array}$ & $\begin{array}{c}116.5 \\
4\end{array}$ \\
\hline 6 , & $\begin{array}{c}128.8 \\
7\end{array}$ & $\begin{array}{c}131.5 \\
3\end{array}$ & $\begin{array}{c}121.8 \\
1\end{array}$ & $\begin{array}{c}130.8 \\
6\end{array}$ & $\begin{array}{c}128.0 \\
5\end{array}$ & $\begin{array}{c}128.0 \\
9\end{array}$ & $\begin{array}{c}130.8 \\
6\end{array}$ & $\begin{array}{c}121.8 \\
1\end{array}$ & $\begin{array}{c}121.8 \\
1\end{array}$ & $\begin{array}{c}128.8 \\
7\end{array}$ & $\begin{array}{c}130.8 \\
6\end{array}$ & $\begin{array}{c}128.0 \\
5\end{array}$ \\
\hline $7^{\prime}$ & $\begin{array}{c}119.8 \\
4\end{array}$ & $\begin{array}{c}125.4 \\
5\end{array}$ & $\begin{array}{c}116.5 \\
3\end{array}$ & $\begin{array}{c}135.5 \\
4\end{array}$ & $\begin{array}{c}135.4 \\
9\end{array}$ & $\begin{array}{c}124.7 \\
2\end{array}$ & $\begin{array}{c}135.5 \\
4\end{array}$ & $\begin{array}{c}116.5 \\
3\end{array}$ & $\begin{array}{c}116.5 \\
3\end{array}$ & $\begin{array}{c}119.8 \\
4\end{array}$ & $\begin{array}{c}135.5 \\
4\end{array}$ & $\begin{array}{c}135.4 \\
9\end{array}$ \\
\hline $8^{\prime}$ & $\begin{array}{c}128.7 \\
6\end{array}$ & $\begin{array}{c}131.7 \\
4\end{array}$ & $\begin{array}{c}148.9 \\
9\end{array}$ & $\begin{array}{c}133.6 \\
3\end{array}$ & $\begin{array}{c}132.4 \\
3\end{array}$ & $\begin{array}{c}167.1 \\
4\end{array}$ & $\begin{array}{c}133.6 \\
3\end{array}$ & $\begin{array}{c}148.9 \\
9\end{array}$ & $\begin{array}{c}148.9 \\
9\end{array}$ & $\begin{array}{c}128.7 \\
6\end{array}$ & $\begin{array}{c}133.6 \\
3\end{array}$ & $\begin{array}{c}132.4 \\
3\end{array}$ \\
\hline $9^{\prime}$ & $\begin{array}{c}126.2 \\
5\end{array}$ & $\begin{array}{c}116.5 \\
4\end{array}$ & $\begin{array}{c}167.0 \\
8\end{array}$ & $\begin{array}{c}119.8 \\
6\end{array}$ & $\begin{array}{c}120.2 \\
6\end{array}$ & $\begin{array}{c}124.7 \\
2\end{array}$ & $\begin{array}{c}119.8 \\
6\end{array}$ & $\begin{array}{c}167.0 \\
8\end{array}$ & $\begin{array}{c}167.0 \\
8\end{array}$ & $\begin{array}{c}126.2 \\
5\end{array}$ & $\begin{array}{c}119.8 \\
6\end{array}$ & $\begin{array}{c}120.2 \\
6\end{array}$ \\
\hline $10^{\prime}$ & $\begin{array}{c}160.9 \\
4\end{array}$ & $\begin{array}{c}167.1 \\
3\end{array}$ & $\begin{array}{c}119.8 \\
3\end{array}$ & $\begin{array}{c}128.3 \\
4\end{array}$ & $\begin{array}{c}125.1 \\
5\end{array}$ & $\begin{array}{c}128.0 \\
9\end{array}$ & $\begin{array}{c}128.3 \\
4\end{array}$ & $\begin{array}{c}119.8 \\
3\end{array}$ & $\begin{array}{c}119.8 \\
3\end{array}$ & $\begin{array}{c}160.9 \\
4\end{array}$ & $\begin{array}{c}128.3 \\
4\end{array}$ & $\begin{array}{c}125.1 \\
5\end{array}$ \\
\hline 1" & 55.82 & 65.63 & 55.81 & 55.57 & 65.53 & 55.81 & 55.57 & 55.81 & 55.81 & 55.82 & 55.57 & 65.53 \\
\hline $2 "$ & 31.10 & 31.13 & 20.72 & 31.17 & 31.11 & 31.08 & 31.17 & 20.72 & 20.72 & 31.10 & 31.17 & 31.11 \\
\hline 3" & 41.56 & 41.55 & 41.52 & 41.65 & 41.53 & 41.53 & 41.65 & 41.52 & 41.52 & 41.56 & 41.65 & 41.53 \\
\hline $\begin{array}{c}\mathrm{Me} \\
\mathrm{O}\end{array}$ & 55.31 & 55.81 & 55.70 & 53.57 & 55.84 & 53.42 & 53.57 & 55.70 & 55.70 & 55.31 & 53.57 & 55.84 \\
\hline $\begin{array}{c}\mathrm{Me} \\
\mathrm{O}\end{array}$ & - & - & 53.12 & - & - & - & - & 53.12 & 53.12 & - & - & - \\
\hline
\end{tabular}

The characterization of compound $\mathbf{1 2}$ by spectral methods was presented (Table-1 and 2). The Yellow color solid compound 12exhibited a pseudo molecular ion peak at $\mathrm{m} / \mathrm{z} 485.9$ for $[\mathrm{M}+\mathrm{H}]^{+}$ion in its electron spray ionization positive mode mass spectrum analyzing for a molecular formulae $\mathrm{C}_{23} \mathrm{H}_{21} \mathrm{ClN}_{4} \mathrm{O}_{6}$. In its IR spectrum, it showed characteristic absorption bands at $1680 \mathrm{~cm}^{-1}$ for carbonyl, $3342 \mathrm{~cm}^{-1}$ for N-H, $1180 \mathrm{~cm}^{-1}$ for C-O and at $2224 \mathrm{~cm}^{-1}$ for $\mathrm{CN}$ groups. In its ${ }^{1} \mathrm{H}-\mathrm{NMR}$ spectra, it exhibited singlet's at $\delta 8.7$ $(1 \mathrm{H}, \mathrm{H}-2), 7.58(1 \mathrm{H}, \mathrm{H}-5), 7.04(1 \mathrm{H}, \mathrm{H}-8)$ for the protons of the quinoline ring system. The strong singlet at $\delta 3.8$ is attributed to the methoxy group protons present in the quinoline ring system. The signals at $\delta$ $2.07(2 \mathrm{H}, \mathrm{m}, \mathrm{H}-2$ '' $), 4.11\left(2 \mathrm{H}, \mathrm{t}, \mathrm{H}-1{ }^{\prime}, ', \mathrm{~J}=6.2 \mathrm{~Hz}\right)$ and at $\delta 3.66(2 \mathrm{H}, \mathrm{t}, \mathrm{H}-3$ '', J=6.4 Hz) were assigned to the 3-chloropropoxy group. The $-\mathrm{O}-\mathrm{CH}_{2}-\mathrm{CO}$ methylene protons appeared as a singlet at $\delta 5.06$ and the $\mathrm{N}=\mathrm{CH}$ proton appeared at $\delta 7.9$ as a singlet. The meta coupled signal at $\delta 7.2(1 \mathrm{H}, \mathrm{d}, \mathrm{J}=1.6 \mathrm{~Hz})$, the doublet at $\delta 6.8(1 \mathrm{H}, \mathrm{d}, \mathrm{J}=8 \mathrm{~Hz})$ and a multiplet at $\delta 7.03(1 \mathrm{H}, \mathrm{m})$ were due to the phenyl ring protons. Complementing the above data the ${ }^{13} \mathrm{C}$-NMR spectra exhibited characteristic signals at $\delta 172.7$ for the carbonyl carbon, at $\delta 31.11,41.53$ and 65.53 for the carbons of the 3-chloropropoxy group and at $\delta 55.8$ for methoxy carbon. It also exhibited signals at $\delta 119.86$ for $\mathrm{CN}$ carbon(C-11'), 79.09 for the methylene carbon in between oxygen and carbonyl functions $\left(\mathrm{C}^{-1} 1^{\prime}\right)$ and at 145.5 for $\mathrm{C}=\mathrm{N}$ carbon $\left(\mathrm{C}-4^{\prime}\right)$. All the aromatic carbons appeared between $\delta 93.01$ and 152.71 . 
RASĀYAN J. Chem.

Vol. 12 | No. 2 |880 - 890| April - June | 2019

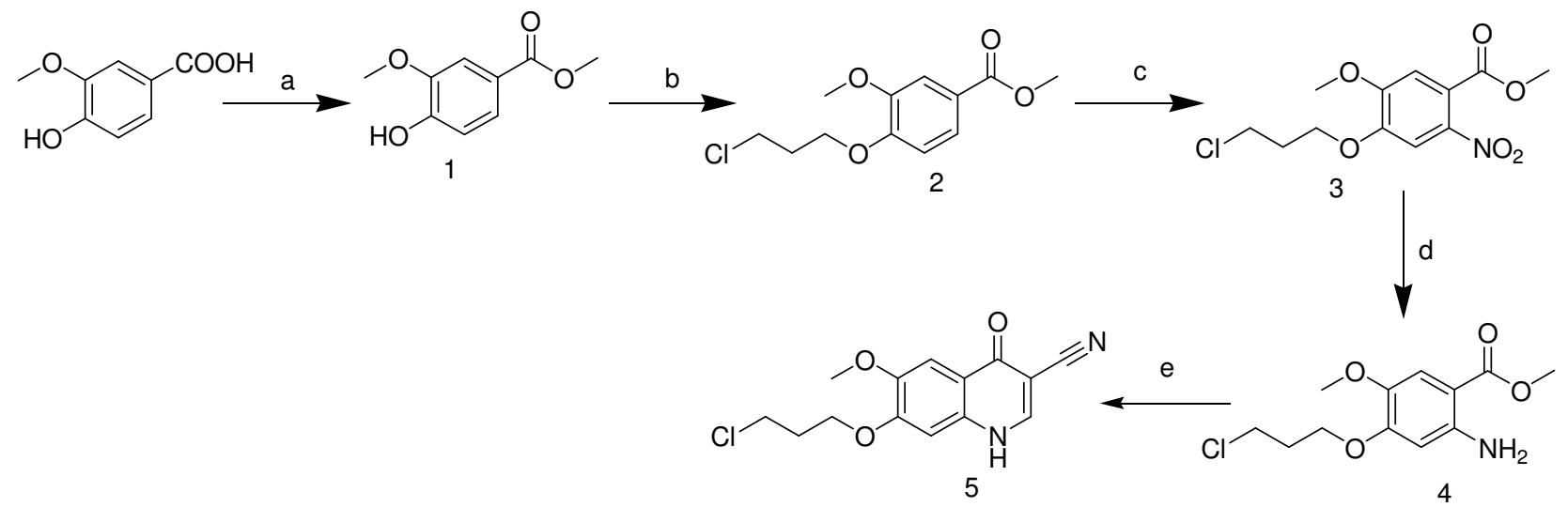

Scheme-1: Reagents and Conditions: (a) $\mathrm{MeOH}, \mathrm{CH}_{3} \mathrm{COCl}, 60-65^{\circ} \mathrm{C}$. (b) DMF, 1-Bromo-3-Chloropropane, $\mathrm{K}_{2} \mathrm{CO}_{3}$ (c) $\mathrm{CH}_{3} \mathrm{COOH}, \mathrm{HNO}_{3}$ (d) Fe, $\mathrm{NH}_{4} \mathrm{Cl}$, DM Water (e)DM Water, $\mathrm{CF}_{3} \mathrm{COOH}$. 3,3-Diethoxypropionitrile, Sodium Hydroxide, Ethanol.<smiles></smiles><smiles>[R]c1cccc(/C=N/NC(=O)COc2c(C#N)cnc3cc(OCCCCl)c(OC)cc23)c1</smiles>

Scheme-2: Reagents and Conditions: (a) Acetone, $\mathrm{K}_{2} \mathrm{CO}_{3}$, Ethyl Bromoacetate, EtOH, 55-60 ${ }^{\circ} \mathrm{C}$. (b) EtOH, Hydrazine Hydrate $(99 \%), 75-80^{\circ} \mathrm{C}$.(c) EtOH, p-TSA, SubstutedAr-CHO.

\section{Anticancer Activity}

Leukemia is a most dangerous haematological malignant cancer and found to be very sensitive to anticancer chemotherapeutic agents, which either interfere with the cell cycle or cause apoptosis. This has encouraged scientists to search for more specific and effective drugs against it. Hence, the cytotoxic effect of 7-19 against CML cells (K562) was studied using Trypan blue, MTT and LDH assay (Table-3). The procedures reported in our earlier study were followed for the above assays ${ }^{9-11}$. The principle of MTT assay is the transformation of the yellow tetrazolium bromide (MTT) to a purple formazan derivative by mitochondrial succinate dehydrogenase in viable cells. K562 cells treated with $6.25,12.5$, 50, and 100 $\mu \mathrm{g} / \mathrm{ml}$ of compounds 7-19 were harvested after $24 \mathrm{~h}$ and subjected to MTT assay. 
All the compounds 7-19 were tested in triplicate, thus the reported $\mathrm{IC}_{50}$ values are an average of these three measurements. Most of the newly synthesized compounds showed promising activity against CML K562 cell lines. The results showed (Table 3) that cell viability was affected upon treatment with of the compounds 7-19 in a dose-dependent manner. These results also showed that the activity against cancer cells depends on the chemical nature of the substituent present in the phenyl ring of the hydrazide system.

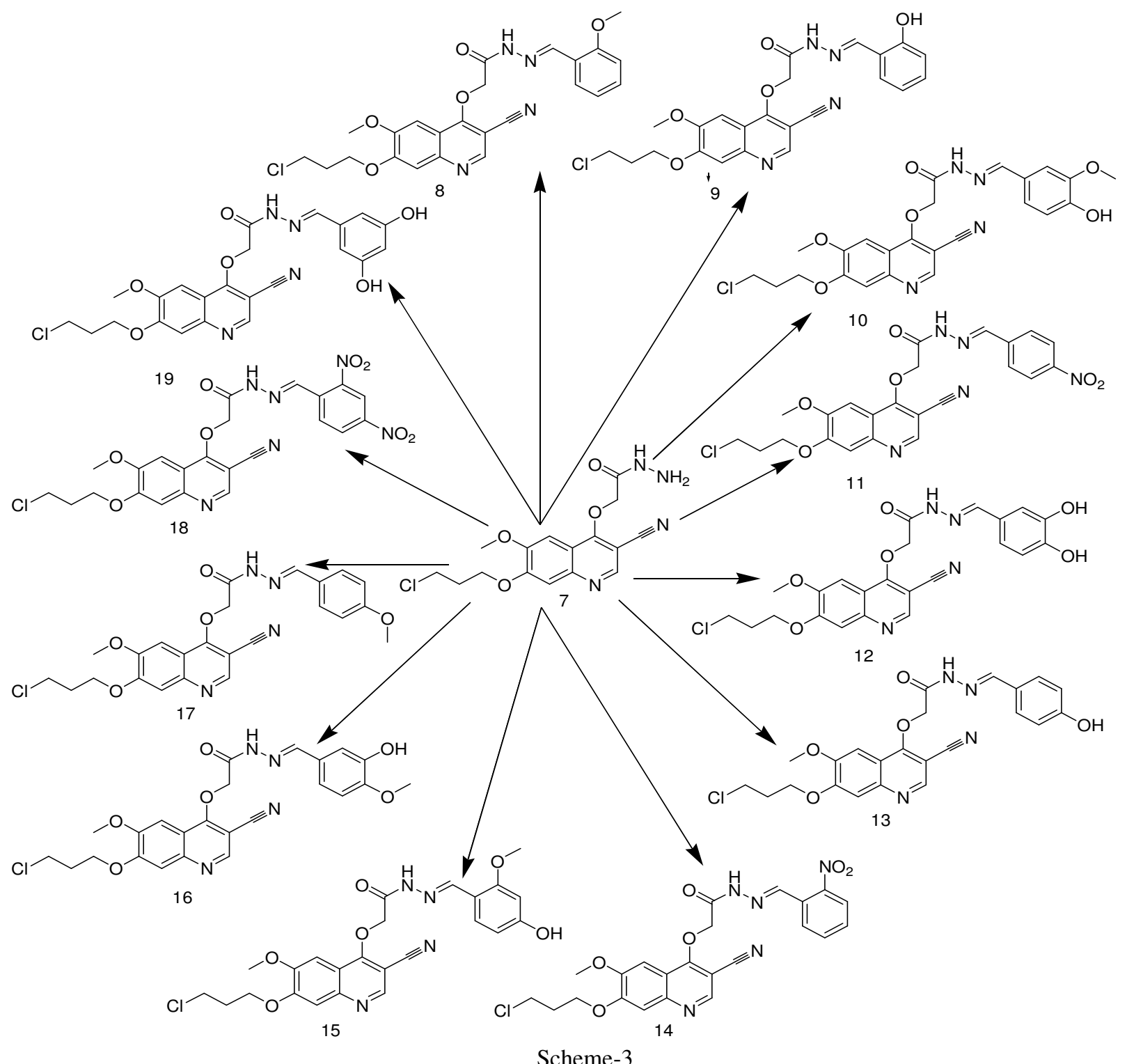

Comparing the $\mathrm{IC}_{50}$ data for the tested compounds it could be noted that the quinoline molecules with strong electron donating groups $(\mathrm{OH}, \mathrm{MeO}) \mathbf{8 , 9}, 10,12$ and 13 are more active, than compound 11 with an electron withdrawing group $\left(\mathrm{NO}_{2}\right)$. Among the compounds with electron donating group's compound $\mathbf{9}$ with $\mathrm{OH}$ group is more active than the compound $\mathbf{8}$ with $\mathrm{MeO}$ group. Between the compounds $\mathbf{9}$ and $\mathbf{1 3}$ where the $\mathrm{OH}$ group is in the ortho and Para positions of the phenyl ring, compound $\mathbf{1 3}$ with the Para $\mathrm{OH}$ group is found to be more active than the corresponding ortho isomer. The Meta and Para disubstituted compounds $\mathbf{1 0}$ and $\mathbf{1 2}$ are more active than the monosubstituted compounds. Within the compounds $\mathbf{1 0}$ and 12, the compound $\mathbf{1 2}$ with two hydroxyl groups in the Meta and Para position is more active than $\mathbf{1 0}$ with a methoxy group in the meta position and an $\mathrm{OH}$ group in the Para position. Compound $\mathbf{1 2}$ is found to be more active among all the tested compounds with an $\mathrm{IC}_{50}$ value of $26.93 \pm 2.8 \mu \mathrm{g} / \mathrm{ml}$. However, when it is compared with the standard compound bosutanib ( $\mathrm{IC}_{50}$ value of $8.12 \pm 0.2 \mu \mathrm{g} / \mathrm{ml}$ ) the activity is 
less. Compounds 7-19 also exhibits the anticancer activity, but the activity is less when compared with the compounds 7-19. It proved that the incorporation of hydrazide moiety (-CONHNH) in the quinoline ring is important for enhancing the cytotoxic activity of these compounds. The same trend was reported in theliterature also for another series of molecules ${ }^{12}$. Thus, the above results indicate that these simple quinolinehydrazides are interesting models in the development of new anticancer agents. Finally, these results would be a promising study for future more potent anticancer quinoline drugs.

Table-3: $\mathrm{IC}_{50}$ Value of 7-19 analyzed by Trypan Blue and MTT Assay

\section{Trypan Blue Assay}

\begin{tabular}{c|c|c}
\hline \multirow{2}{*}{ Sample } & \multicolumn{2}{|c}{$\mathrm{IC}_{50}(\mu \mathrm{g} / \mathrm{ml})^{*}$} \\
\cline { 2 - 3 } & Trypan Blue & MTT \\
\hline 7 & $36.13 \pm 2.5$ & $37.38 \pm 5.2$ \\
\hline 8 & $37.51 \pm 6.4$ & $33.34 \pm 1.6$ \\
\hline 9 & $34.8 \pm 2.2$ & $34.26 \pm 1.3$ \\
\hline 10 & $30.03 \pm 3.1$ & $27.14 \pm 4.6$ \\
\hline 11 & $37.51 \pm 6.4$ & $38.56 \pm 5.5$ \\
\hline 12 & $28.92 \pm 1.6$ & $26.93 \pm 2.8$ \\
\hline 13 & $31.03 \pm 3.3$ & $31.06 \pm 3.2$ \\
\hline 14 & $56.39 \pm 1.2$ & $59.32 \pm 2.8$ \\
\hline 15 & $37.51 \pm 3.7$ & $40.46 \pm 3.3$ \\
\hline 16 & $40.68 \pm 3.8$ & $42.87 \pm 1.3$ \\
\hline 17 & $56.19 \pm 2.2$ & $49.95 \pm 3.1$ \\
\hline 18 & $41.46 \pm 4.1$ & $47.69 \pm 4.8$ \\
\hline 19 & $38.12 \pm 1.0$ & $42.66 \pm 5.3$ \\
\hline Bosutanib & $6.12 \pm 1.1$ & $8.12 \pm 0.2$ \\
\hline
\end{tabular}

To evaluate the cytotoxic effect of the synthesized hybrid compounds on the growth of leukemia cells, we also used trypan blue assay. Compounds 7-19 exhibited cytotoxicity against leukaemia cells in a dosedependent manner. $\mathrm{IC}_{50}$ values were calculated and presented in the table-3. Regarding the SAR study it confirms the trend observed in MTT assay (Fig.-2).

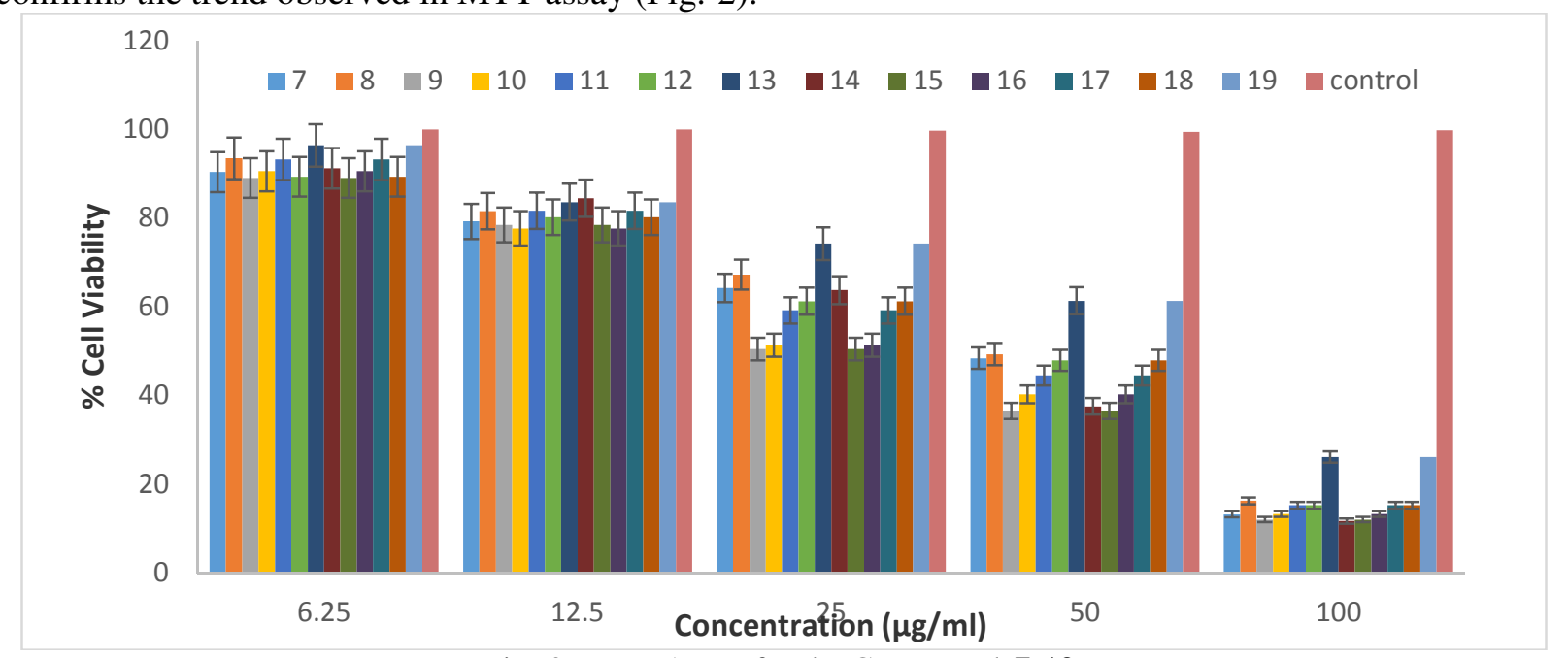

\section{LDH Assay}

Fig.-2: MTT Assay for the Compounds7-19.

To further check the cytotoxic effect of the compounds 7-19, LDH release in cell culture suspension was measured using LDH assay (Fig. 3). Methanol-treated cells were used as vehicle control, and cells treated with 7-19 showed LDH release, suggesting a cytotoxic effect on K562 cells. The membrane of K562 cells was disrupted due to the cytotoxic effect of 7-19, causing the release of lactate dehydrogenase (LDH) into the supernatant. The results showed a dose-dependent increase in LDH release upon treatment with 7-19, further confirming the results above. 


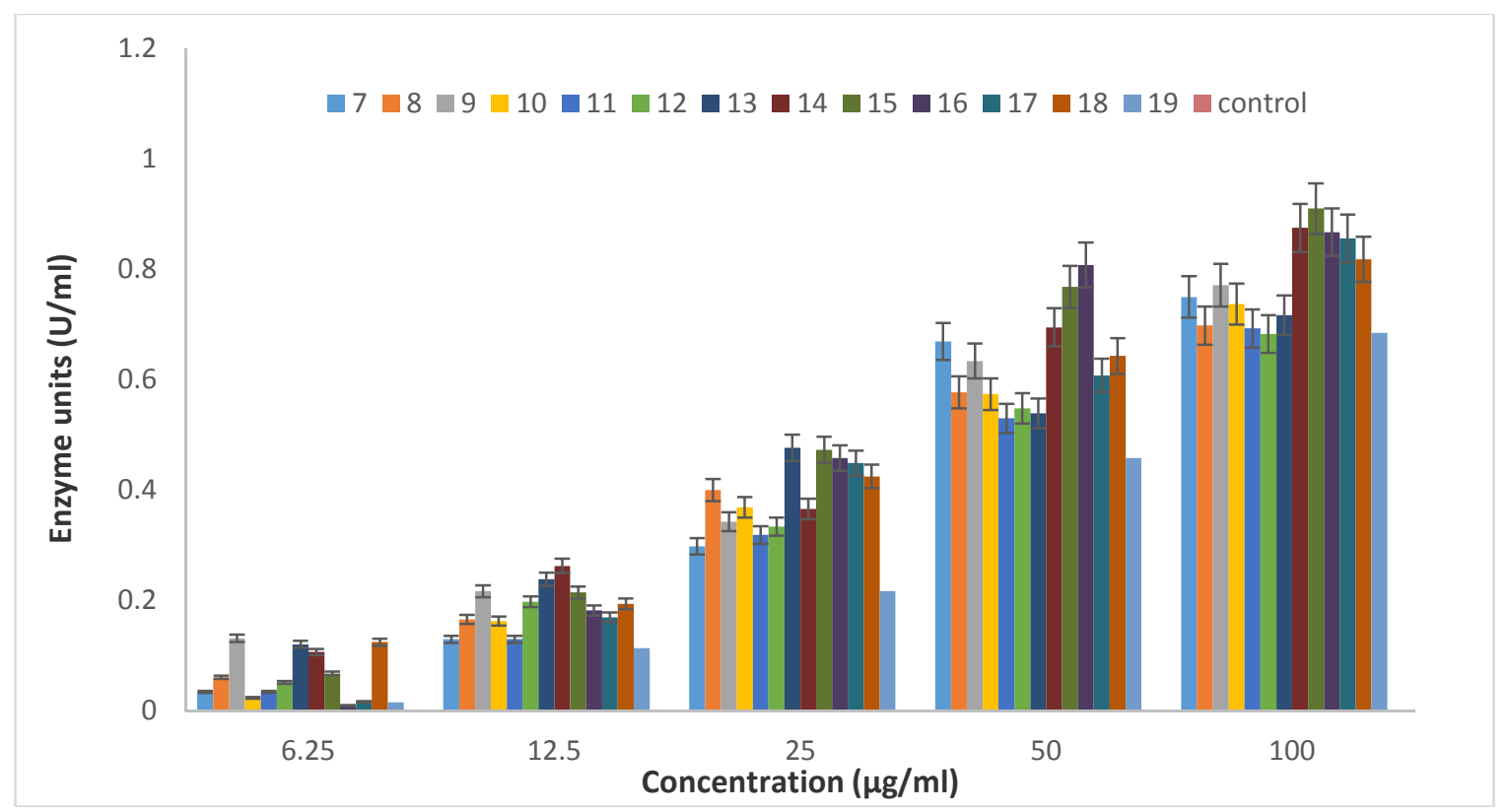

Fig.-3: Measurement of LDH release Following Treatment with 7-19.

After the contact of K562 with 7-19 at different concentrations $(6.25,12.5,50$ and $100 \mu \mathrm{g} / \mathrm{ml})$ for $24 \mathrm{~h}$, the release of $\mathrm{LDH}$ was measured at $490 \mathrm{~nm}$. The data presented is the result of three independent experiments and error bar are indicated.

\section{Molecular Docking Studies}

To predict the binding mode of the newly synthesized active compounds, a docking study was performed using AutoDock Vina. The Lamarckian genetic algorithm (LGA) available in AutoDock Vina was employed for docking. To perform molecular docking, the three-dimensional (3D) structure of 2VA7(tyrosine kinase Bcr-Abl (T315I)protein) was obtained from Protein Data Bank and the ligand structures 7-19 were drawn using Chem3D Ultra software. Further, 3D structures were prepared to apply partial charges and energy minimization. The interactions were viewed using Chimera software packages. The results for the binding energy and the length and number of hydrogen bonds formed with the ligand and active site are summarized in Molecules 7-19 showed binding energy between -7.6 and $-8.1 \mathrm{kcal} / \mathrm{mol}$ and formed hydrogen bond with the active site of Bcr-Abl (T315I), thereby suggesting effective inhibition leading to anti-apoptotic protein (Table-3). The more active molecule $\mathbf{1 2}$ the $\mathrm{N}-\mathrm{H}$ group of the quinoline moiety was engaged in a crucial hydrogen bond interaction with the $\mathrm{C}=\mathrm{O}$ group of MET318 in the hinge region while the $\mathrm{O}-\mathrm{H}$ group of the phenyl ring involved in hydrogen bonding with $\mathrm{C}=\mathrm{O}$ group of ASN368 and ARG 367 (Fig.-2). In compound 13 the O-H group showed hydrogen bonding with H-N group of ASN322, $\mathrm{O}=\mathrm{C}$ group of GLY249, Nitrile and $\mathrm{C}=\mathrm{O}$ group groups forms a hydrogen bond with $\mathrm{H}-\mathrm{N}$ group of adenosine triphosphate (ATP) binding site LYS271. The analysis of the structure-affinity relationships suggested that the substituent in the Para position of the phenyl ring is important in influencing affinity. Docking results confirm the same (Fig.-4).

The docking results indicated that the $\mathrm{N}-\mathrm{H}$ group of the quinoline moiety forms hydrogen bonds with the carbonyl group of MET318, the carbonyl group and the nitrile groups' forms hydrogen bonds with LYS271 and the Substituent's in the phenyl ring like O-H group forms hydrogen bonds with ASN368 and ARG 367. In the hydrazide moiety, the N-H group showed interaction with ASP381 and ASP325 involving attractive charges. All the tested compounds showed hydrophobic interactions like alkyl, alkylpi alkyl and Vander walls interaction with ILE315, ALA380, VAL299, LYS271, ALA269, GLY251, GLY321, THR319 and PHE317.

\section{CONCLUSION}

A novel series of quinoline-based hybrid molecules were designed and synthesized for anticancer. The synthesized molecules showed significant in vitro anticancer activity especially against CML Cells 
(K562). Activity results indicated that compounds could be utilized as lead molecules for further chemical. To enhance their therapeutic potential as anticancer agents in the emergence of rapid resistance existing anticancer. Further pharmacological and pharmacokinetic development of these hybrid molecules is currently in progress. From the anti-cancer activity, 10, 11, 12 and 7 shows good activity against K562 cell by concentration-dependent manner.
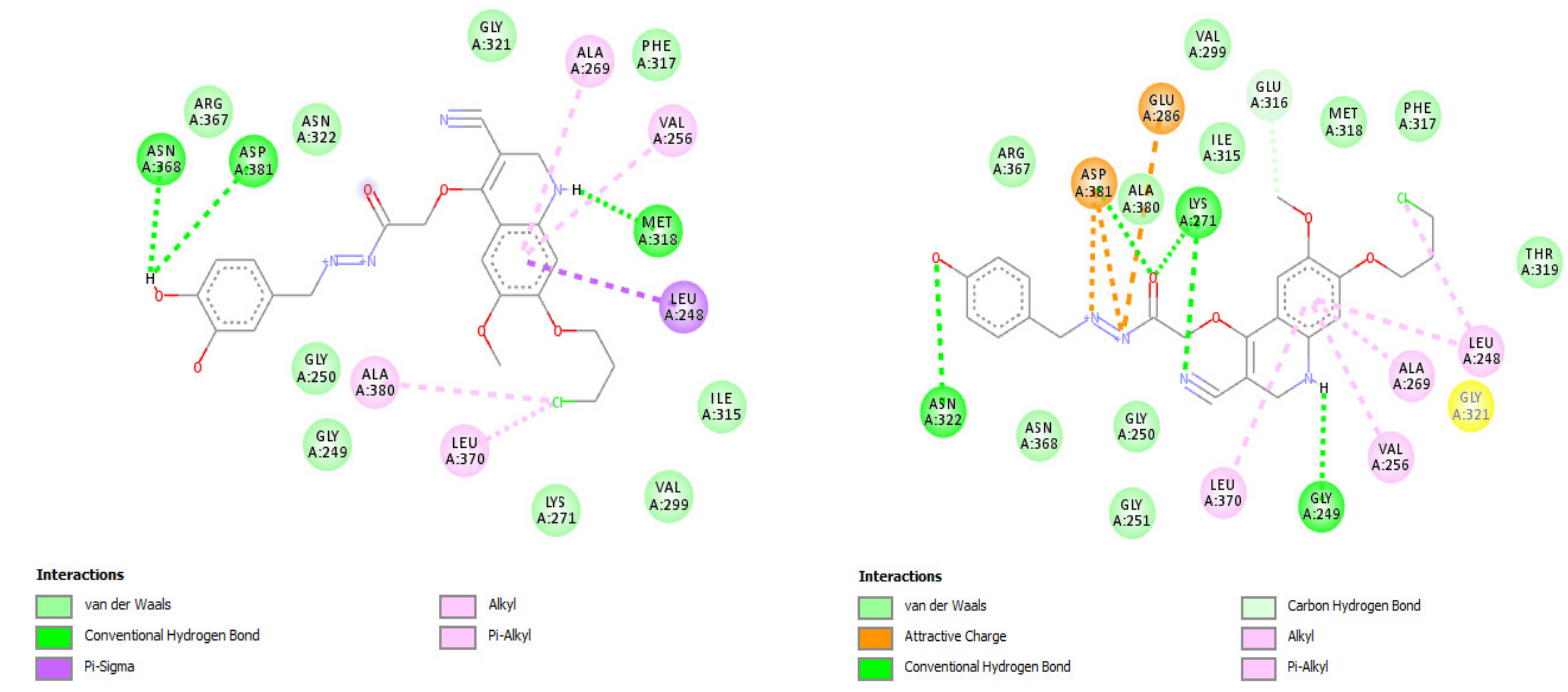

Fig.-4: Docking of the Compounds 12 and 13 against Bcr-Abl (T315I) Protein(PDB id: 2V7A).

\section{REFERENCES}

1. V. Gasparotto, I. Castagliuolo, G. Chiarelotto, V. Pezzi, D. Montanaro, P. Brun, G. Palu, G. Viola, M. G. Ferlin,J. Med. Chem.,49, 1910(2006), DOI:10.1021/jm0510676.

2. F. Schmidt, C. B. Knobbe, B. Frank, H. Wolburg, M. Weller, Onco. Repo., 19, 1061(2008).

3. A. Ryckebusch, R. Derprez-Poulain, L. Maes, D. M. A. Fontaine, E. Mouray, P. Grellier, C. Sergheraert,J. Med. Chem.,46, 542(2003), DOI: 10.1021/jm020960r.

4. M. E. Wall, M. C. Wani, C. E. Cook, K. H. Palmer, A. T. McPhail, G. A. Sim,J. Am.Chem. Soc.,88, 3888 (1966), DOI: 10.1021/ja00968a057.

5. S. K. Srivastava, M. Khan, Khanuja, S.P.K., US 6,893,668 B2 (2005).

6. S. G. Kansara, R. D. Pandit and V. G. Bhawe., Rasayan J. Chem., 2(3), 699(2009).

7. X. J. Yin, Guan Hong Xu, Xu Sun, Yan Peng, Xing Ji, Ke Jiang, Fei Li, Molecules, 15, 4261(2010), DOI: $10.3390 /$ molecules 15064261.

8. A. Vultur, R. Buettner, C. Kowolik, W. Liang, D. Smith, F. Boschelli, R. Jove, Mol Cancer Ther., 7, 1185(2008), DOI: 10.1158/1535-7163.MCT-08-0126.

9. S. Ali Muhammad, A. Thangamani, S. Ravi, Res. Chem. Intermed., 1-28(2017), DOI: 10.1007/s11164-017-2953-0. 2017.

10. Siddhartha Marupati , Rajesh Kumar Gaddam , B. Prasanna, and A. Thirupathaiah, RasayanJ.Chem., 11(2), 661(2018), DOI: 10.31788/RJC.2018.1122062

11. B. Yamini1 and R. Nanthini, Rasayan J. Chem., 11(2), 440(2018), DOI: 10.31788/RJC.2018.1121992

12. Lamiaa Osama, Laila A. Abou-Zeid, Magda N. A. Nasr and Atif S. Tantawy, Der PharmaChemica., 8, 100(2016).

[RJC-5137/2018] 